\title{
Ficus Carica Mediated Synthesis of Simulated Solar Light Driven Nano-sized Zinc Stannate Photocatalyst for the Degradation of Methylene Blue
}

\section{Asia Naqeeb}

University of Azad Jammu and Kashmir

Sirajul Haq ( $\nabla$ cii_raj@yahoo.com )

University of Azad Jammu and Kashmir https://orcid.org/0000-0002-9424-2531

\section{Rimsha Ehsan}

University of Azad Jammu and Kashmir

Muhammad Imran Shahzad

National Center for Physics (NCP)

\section{Nadia Shahzad}

National University of Science and Technology (NUST)

\section{Wajid Rehman}

Hazara University Mansehra

Muhammad Waseem

COMSATS University Islamabad (CUI)

\section{Pervaiz Ahmad}

University of Azad Jammu and Kashmir

\section{Umedjon Khalilov}

University of Antwerp and Academy of Sciences of the Republic of Uzbekistan

\section{Research Article}

Keywords: Environment, Methylene blue, Zinc stannate, Photocatalysis, Degradation

Posted Date: April 20th, 2021

DOI: https://doi.org/10.21203/rs.3.rs-435724/v1

License: (c) (i) This work is licensed under a Creative Commons Attribution 4.0 International License.

Read Full License 


\title{
Ficus carica mediated synthesis of simulated solar light driven nano-sized zinc stannate photocatalyst for the degradation of methylene blue
}

\author{
Asia Naqeeb ${ }^{1}$, Sirajul Haq ${ }^{1 *}$, Rimsha Ehsan ${ }^{1}$, Muhammad Imran Shahzad ${ }^{2}$, Nadia \\ Shahzad $^{3}$, Wajid Rehman ${ }^{4}$, Muhammad Waseem ${ }^{5}$, Pervaiz Ahmad ${ }^{6}$, Umedjon Khalilov ${ }^{7,8}$ \\ ${ }^{1}$ Department of Chemistry, University of Azad Jammu and Kashmir, Muzaffarabad, 13100 \\ Pakistan.
}

${ }^{2}$ Nanosciences and Technology Department (NS \& TD), National Center for Physics (NCP), 44000 Islamabad, Pakistan.

${ }^{3}$ US-Pakistan Centre for Advanced Studies in Energy, National University of Science and Technology (NUST), 44000 Islamabad, Pakistan.

${ }^{4}$ Department of Chemistry, Hazara University Mansehra, 21300 Pakistan.

${ }^{5}$ Department of Chemistry, COMSATS University Islamabad (CUI), Islamabad Pakistan.

${ }^{6}$ Department of Physics, University of Azad Jammu and Kashmir, 13100, Muzaffarabad, Pakistan.

${ }^{7}$ PLASMANT research group, NANOLab Center of Excellence, University of Antwerp, Universiteitsplein 1, 2610 Antwerp, Belgium

${ }^{8}$ Institute of Ion-Plasma and Laser Technologies, Academy of Sciences of the Republic of Uzbekistan, 33 Durmon Yuli Street, Tashkent 100125, Uzbekistan

*Email: cii_raj@yahoo.com

*Phone \#: +92333-9698704

\begin{abstract}
:
The synthesis of zinc stannate nanocomposite $\left(\mathrm{Zn}_{2} \mathrm{SnO}_{4} \mathrm{NC}\right)$ was carried out using an environment friendly process that included the use of Ficus carica (F. carica) leaves extract as a capping and reducing agent. X-ray diffraction (XRD) analysis was used to analyze the structural and crystallographic parameters, and the crystallite was discovered to have cubic geometry. The elemental composition of the studied $\mathrm{Zn}_{2} \mathrm{SnO}_{4} \mathrm{NC}$ was investigated using energy dispersive $\mathrm{X}$ -
\end{abstract}


ray $(\mathrm{EDX})$, which revealed that it was extremely pure. The band gap $(3.12 \mathrm{eV})$ was calculated through Tauc plot using diffuse reflectance (DRS) data where the functional groups were explored through Fourier transform infrared (FTIR) spectroscopy. Prior to the photocatalytic reaction, some preliminary experiments were performed, which proposed that $\mathrm{pH} 9$ is suitable for the mineralization of methylene blue (MB) (10 ppm) in the presence of $20 \mathrm{mg}$ of $\mathrm{Zn}_{2} \mathrm{SnO}_{4}$ $\mathrm{NC}$ and simulated solar light. The $96 \%$ of MB was degraded in 80 min with the degradation rate of $0.038 \mathrm{~min}^{-1}$.

Keywords: Environment; Methylene blue; Zinc stannate; Photocatalysis; Degradation.

\section{Introduction}

The environmental pollution are mainly attributed to the diversifying urbanization and industrialization. Water and soil pollution is caused by the industrial effluents that have been discharged into environment, having negative impacts on all living organism [1]. The high concentration of chemicals, dyes and heavy metals are released into water bodies from dyeing industries polluting the ground and surface water and make it unfit for drinking [2]. Water adulteration via dye discharge from several industries (food processing, paints, cosmetics, textile dyeing, paper making) has captivated major attention because of risk to ecosystem and public health [3]. The making of synthetic dyes is above 7 lac tons/year and greater than $15 \%$ of this synthetic colorant is expelled into water per annum and are proved to be mutagenic, xenobiotic and carcinogenic to living organisms [4]. Dyes effluents from the industries like cosmetic, food, dye synthesis, pulp mill, electroplating, textile, paper, and printing are caused water pollution. The xenobiotic properties and complicated aromatic structure of dyes form them arduous to mineralize. A few of the organic dyes and their related products have mutagenic and carcinogenic effects on humans. There is an urgent need to treat the dyes before their release into the water bodies [5]. Methylene blue (MB), a cationic dye and has many applications including silk, wood, and dying cotton. However MB is not believed to be extremely noxious but it can produce some detrimental results such as quadriplegia, jaundice, cyanosis, shock, diarrhea, increased heart rate, vomiting, and tissue deathin human being. Consecutively, MB containing wastewater should be managed properly before letting out into the water bodies [6].

Various biological, chemical, and physical techniques are used for the elimination of unwanted hazardous compounds from contaminated water comprising membrane separation, advanced 
oxidation, coagulation and adsorption, precipitation, reverse osmosis, and membrane processes [7]. The methods reported to eliminate the dyes from aqueous solution were of physical and chemical nature but these methods are highly expensive and less efficient for the dye degradation. The stability of these dyes is maintained by using chemicals which are toxic in nature and thus add to the toxicity of the environment[8]. Among these, photocatalysis is one of the most important processes. Photocatalysis is widely used for many applications in treatment of wastewater and manifested a fair approach for the abolition of inorganic and organic pollutants including organic dyes, oil leakage, and pesticides that cannot be degraded in natural forms. Nano photocatalysis is a versatile oxidation process, utilized in the eradication of very minute amount of pollutant from air and water streams. It is more efficacious than conventional methods due to the large surface area- to- volume ratio, uniform and controlled particle size, structure, composition. Among nanophotocatalysts, nanocomposites are preferred because they are efficient, economic and easy to synthesize [9]. The binary composites oxides render the electronhole recombination process thus increasing the photocatalytic activity. Zinc stannate is a tertiary oxide semiconductor having band gap $(\sim 3.6 \mathrm{eV})$ and termed as zinc tin oxide (ZTO)[10]. The $\mathrm{Zn}_{2} \mathrm{SnO}_{4}$ depict wide-band semiconductor oxides with the conductivity of n-type, (transparent within the visible light region), they are optimistic for applications in the fields of gas sensors, lithium-ion batteries, solar cells, transparent conductors, lead-free ferroelectrics and photo catalysis[11]. Depending on the molar ratio of the primary components ( $\mathrm{Sn}, \mathrm{Zn}$ and $\mathrm{O}$ ), this material exists in two states: $\mathrm{ZnSnO}_{3}$ of the perovskite-type structure and $\mathrm{Zn}_{2} \mathrm{SnO}_{4}$ of the spineltype structure[12]. Different approaches are used for the preparation of zinc stannate nanocomposite including thermal evaporation calcinations, sol-gel synthesis, mechanical grinding, hydrothermal, and ion-exchange methods. However, these methods not user friendly due to the wide use of toxic chemical reagents and expensive instruments(Baruah sand Dutta 2011). The green method is one of the most effective, safe and low cost process and is a possible alternate of the conventional methods[14].

The present study was conducted to mineralize MB from aqueous solution on illumination of simulated solar light irradiation using $\mathrm{Zn}_{2} \mathrm{SnO}_{4} \mathrm{NC}$ as photocatalyst. The $\mathrm{Zn}_{2} \mathrm{SnO}_{4} \mathrm{NC}$ was synthesized via ecofriendly and economic process using $F$. carica leaves extract which belongs to the family Moraceae [15]. The physicochemical properties was analyzed through FTIR, DRS, EDX, XRD, and SEM techniques. The photocatalytic degradation of MB was examined under 
the effects of initial concentration, $\mathrm{pH}$ and catalyst dose. The stability of the $\mathrm{Zn}_{2} \mathrm{SnO}_{4} \mathrm{NC}$ as photocatalyst was also evaluated for several stage degradation process.

\section{Materials and Methods}

\subsection{Materials}

Analytical-grade chemicals were used in this research work. The zinc chloride dihydrate, tin chloride dihydrate, sodium hydroxide, and methylene blue were given by Sigma Aldrich and were used without further purification. All of the requisite solutions were made with deionized water. The botany department classified the $F$. carica leaves that were collected from the chemistry department's lawn.

\subsection{Preparation of Extract}

The $F$. carica leaves were picked, washed in deionized water to remove dust, and then dried in the shade. To make the extract, $50 \mathrm{~g}$ of dried leaves were placed in an airtight jar with $1000 \mathrm{~mL}$ boiled and deionized water and left for 24 hours. The crude extract was then purified and centrifuged for 10 minutes at $4000 \mathrm{rpm}$, with the upper layer being saved for future experiments.

\subsection{Synthesis of $\mathrm{Zn}_{2} \mathrm{SnO}_{4} \mathrm{NC}$}

For the fabrication of $\mathrm{Zn}_{2} \mathrm{SnO}_{4} \mathrm{NC}$, the calculated amount $\left(1.05 \mathrm{~g}\right.$ ) of $\mathrm{ZnCl}_{2} .2 \mathrm{H}_{2} \mathrm{O}$ was solvated in $50 \mathrm{~mL}$ deionized water and $20 \mathrm{~mL}$ of the prepared plant extract was introduced. The $\mathrm{pH}$ of the reaction mixture was fixed at 10 by dropwise addition 0.1 molar solution of $\mathrm{NaOH}$ and was then stirred $(250 \mathrm{rpm})$ and heated $\left(50^{\circ} \mathrm{C}\right)$ for $30 \mathrm{~min}$. The white gel formed was aged at room temperature for $6 \mathrm{~h}$. At the same time, the $\mathrm{SnCl}_{2} .2 \mathrm{H}_{2} \mathrm{O}(0.95 \mathrm{~g})$ was solvated in $50 \mathrm{~mL}$ deionized water and $20 \mathrm{~mL}$ of the plant extract was introduced and stirred $(250 \mathrm{rpm})$ and heated $\left(50{ }^{\circ} \mathrm{C}\right)$ for $30 \mathrm{~min}$ and white gel formed that was aged for $6 \mathrm{~h}$. Afterward, both the gel were mixed with constant stirring $\left(300{ }^{\circ} \mathrm{C}\right)$ and heating $\left(50{ }^{\circ} \mathrm{C}\right)$ for $5 \mathrm{~h}$ at room temperature and was then aged for $24 \mathrm{~h}$. The final product was repeatedly washed with deionized water and was oven dried at $150{ }^{\circ} \mathrm{C}$ and stored in air tight polyethylene bottle.

\subsection{Characterization}


The different physicochemical techniques were utilized for the inspection of the structural and surface properties of the synthesized $\mathrm{Zn}_{2} \mathrm{SnO}_{4} \mathrm{NC}$. The XRD model Panalytical XPert Pro was utilized to analyze the crystalline nature of powder. The XRD quantification was made of $20^{\circ}$ to $80^{\circ}$ in $2 \theta$ range and Debye-Scherrer equation was employed for determining the average crystallite size. Morphology was studied by using SEM model JEOL 5910 (Japan). The band gap was determined from data obtained by running DRS (lambda 950) in the 400-1000 nm range using Tauc's plot. The material's elemental analysis was performed on an EDX model INCA200 (UK) operating in the $1-20 \mathrm{keV}$ scale. The FTIR spectrum was recorded using a Nicolet 6700 (USA) spectrometer in the range of $4000-400 \mathrm{~cm}^{-1}[16]$.

\subsection{Photocatalytic activity}

During the photocatalytic removal of $\mathrm{MB}$, the photocatalytic behavior of the assynthesized $\mathrm{Zn}_{2} \mathrm{SnO}_{4} \mathrm{NC}$ was examined. To begin, a $10 \mathrm{ppm} \mathrm{MB}$ solution was made in deionized water, and $50 \mathrm{~mL}$ of that solution was poured into a reaction vessel, along with $20 \mathrm{mg}$ of $\mathrm{Zn}_{2} \mathrm{SnO}_{4} \mathrm{NC}$. The reaction mixture was mixed in the dark for $30 \mathrm{~min}$ to obtain the adsorptiondesorption equilibrium. The solution was then subjected to artificial solar radiation. To extract the catalyst, the $3 \mathrm{~mL}$ sample was centrifuged at $4000 \mathrm{rpm}$ for $4 \mathrm{~min}$ after a fixed time interval (in min). On a spectrophotometric analysis of the centrifuged sample using a double beam spectrophotometer, the absorbance limit was recorded as a function of time (Thermo Spectronic UV 500).

\section{Results and discussion}

\subsection{Physicochemical study}

The diffractogram shown in Fig. 1 possess characteristics Bragg's reflections at $2 \theta$ positions with hkl values 30.05(220), 37.32(222), 47.63(331), 50.90 (422), 56.75(511), 57.65(531), 62.70(440), 68.12(620), 70.10(533) and 79.35(622). These bands correspond to those listed in JCPDS card 00-024-1470, which confirm the synthesis of $\mathrm{Zn}_{2} \mathrm{SnO}_{4} \mathrm{NC}$ having $\mathrm{Fd} 3 \mathrm{~m}$ space group and cubic geometry. The length of three coordinates ( $a, b$ and $c$ ) of the cubic $\mathrm{Zn}_{2} \mathrm{SnO}_{4} \mathrm{NC}$ are equal to $8.5674 \AA$ whereas the angles alpha, beta and gamma are of $90^{\circ}$. The intense and sharp diffraction bands confirm the formation of well crystalline nanostructures and all peaks were assigned to the desired elements, suggesting the synthesized samples are highly pure. The crystallite size for 
$\mathrm{Zn}_{2} \mathrm{SnO}_{4} \mathrm{NC}$ was quantified by Debye-Scherrer's equation is $42.47 \mathrm{~nm}$ along with $0.32 \%$ imperfection was also found in the crystal.

\section{(Position for Fig.1)}

The EDX spectrum of $\mathrm{Zn}_{2} \mathrm{SnO}_{4} \mathrm{NC}$ shown as inset in Fig. 1, exhibits the bands assigned to $\mathrm{Sn}$, $\mathrm{Zn}$ and $\mathrm{O}$, which confirm the synthesis of highly pure $\mathrm{Zn}_{2} \mathrm{SnO}_{4} \mathrm{NC}$. The peaks in the range of 3.4 to $3.9 \mathrm{keV}$ are attributed to $\mathrm{Sn}$ along with a sharp signal at $0.4 \mathrm{keV}$ is credited to $\mathrm{O}$ in the sample. The three bands at $1,8.7$ and $9.6 \mathrm{keV}$ are due to the $\mathrm{Zn}$ and the weight percentages derived from the EDX data for $\mathrm{Zn}, \mathrm{Sn}$, and $\mathrm{O}$ are 42.95, 36.33 and $20.71 \%$ respectively. The SEM micrographs (low and high magnification)given in Fig.2, shows randomly arranged intraparticles cavities. The small particles areclosely connected with each other forming larger various shaped structures specially the cauliflower like at the right lower corner of the image (b). On close observation, small individual particles with almost uniform shape are present on the surface of the complex structures. The histogram located on the left corner of image (a) shows two sharp peaks at 50 and 104 suggesting that theparticles size is ranging from 50 to $104 \mathrm{~nm}$ with the average of $79 \mathrm{~nm}$.

\section{(Position for Fig. 2)}

The electronic state of the $\mathrm{Zn}_{2} \mathrm{SnO}_{4} \mathrm{NC}$ was calculated using the transmittance spectrum, which indicates that all of the samples are translucent over a broad wavelength range. The band gap energies were determined using the Tauc relation (eq.1), where $B$ is constant, $h v$ is the light intensity, is the absorption coefficient, and the exponent $n$ is depending on the type of transition: direct, forbidden direct, indirect, or forbidden indirect, and can have values of $1 / 2,2,3 / 2$, or 3 respectively [17].

$$
\alpha h v=B\left(h v-E_{g}\right)^{n}
$$

The $\alpha$ and transmittance are correlated as given in eq. 2, where $L$ is the thickness of the sample for direct allowed transition $(n=1 / 2)$, by combining eq. 1 and eq. 2 , we have;

$$
\begin{aligned}
& T=\exp (-\alpha L) O R \alpha=-\ln T / L \\
& (h v \ln T)^{2}=B^{2} L^{2}\left(h v-E_{g}\right)
\end{aligned}
$$




\section{(Position for Fig. 3)}

The band gap energies were calculated for $\mathrm{Zn}_{2} \mathrm{SnO}_{4} \mathrm{NC}$ from Tauc plots by joining sharp rising portion with horizontal axis of the $(h v \ln T)^{2}$ against $h v$ is $3.12 \mathrm{eV}[18,19]$. The band gap energy for $\mathrm{Zn}_{2} \mathrm{SnO}_{4} \mathrm{NC}$ is divergent from that of $\mathrm{SnO}_{2} \mathrm{NPs}$ and $\mathrm{ZnO}$ NPs suggesting that the production of new species and all the deduced band gap energies are in accordance with the reported data [20-25]. In the FTIR spectrum of $\mathrm{Zn}_{2} \mathrm{SnO}_{4} \mathrm{NC}$ (Fig.4), the peaks at 3489.2, 3438.9 and 1634.4 $\mathrm{cm}^{-1}$ are because of the deformation, stretching and bending vibrations of adsorbed water molecules[26]. The stretching vibration of O-Sn-O in the lattice system and potential bonding of $\mathrm{Zn}$ in $\mathrm{ZnO}$ are attributed to the small broad peaks at 1484.53 and $1402.61 \mathrm{~cm}^{-1}$, respectively [22]. The stretching vibrations of $\mathrm{ZnO}$ and $\mathrm{SnO}_{2}$ pairs, which can be due to the $\mathrm{Sn}-\mathrm{O}-\mathrm{Zn}$ bonding in $\mathrm{Zn}_{2} \mathrm{SnO}_{4}$, are responsible for the peaks at 719.4 and $550.47 \mathrm{~cm}^{-1}$ [27].

\section{(Position for Fig.4)}

\subsection{Photocatalytic study}

The photocatalytic potency of $\mathrm{Zn}_{2} \mathrm{SnO}_{4} \mathrm{NC}$ was analyzed to degrade $\mathrm{MB}$ with the catalyst concentration of $20 \mathrm{mg}$ on irradiating simulated solar light. The visual photodegradation of MB was observed due to the fading of color with the increase in irradiation time. The eq. 4 was used to determine the percentage degradation (Fig. 5), that inferred $96 \%$ of the dye was mineralized in 80 min of contact with the catalyst under simulated solar light. The self-photolysis was also performed on irradiation of simulated solar light without introducing catalyst and it was observed that there was a minor reduction of the original concentration of the MB solution which assures the stability of the MB dye. This infers that the $\mathrm{Zn}_{2} \mathrm{SnO}_{4} \mathrm{NC}$ is highly effective and the dye would not be degraded without it. The Langmuir-Hinshelwood kinetic model (eq. 5) was applied for the kinetic modeling of the kinetic data where $C$ is the concentration at time $(t), C_{e}$ is the initial concentration whereas $k$ is the rate constant. A straight line is obtained by plotting $\ln (\mathrm{C} / \mathrm{Co})$ versus time $(t)$ shows that the photocatalytic degradation reaction obeys pseudo first order kinetics and the $\mathrm{k}$ value was found to be $0.038 \mathrm{~min}^{-1}$.

$$
\begin{gathered}
\% \text { Degradation }=\frac{\mathrm{Ct}-\mathrm{Co}}{C o} \times 100 \\
\ln (C / C o)=-k t
\end{gathered}
$$




\section{(Position for Fig. 5)}

\section{Dosage study}

The $10 \mathrm{ppm} \mathrm{MB}$ was exposed different quantities of the $\mathrm{Zn}_{2} \mathrm{SnO}_{4} \mathrm{NC}(5,10,15,20,25$ and 30 $\mathrm{mg}$ ) to check the affect of catalyst dosage on the catalytic mineralization process. From the experiment Fig. 6(A), it was inferred that the degradation of MB increases with increasing the dose of catalyst up to $20 \mathrm{mg}$ while further elevation in the dose reduced the degradation process. This decrease in the degradation is attributed to the phenomenon of deactivation of catalyst. When large amount of catalyst is introduced to the solution collision ensues between the activated and the ground state catalyst that leads to the deactivation of the activated molecules and consequently degradation decreases [28].

\subsubsection{Initial concentration study}

In the present work, 5, 10, 20, 30 and $40 \mathrm{ppm} \mathrm{MB}$ solutions were unveiled to the $\mathrm{Zn}_{2} \mathrm{SnO}_{4} \mathrm{NC}$ to scrutinize the effect of dye concentration on the photocatalytic mineralization. The results shows Fig. 6(B)that the degradation increases with increasing initial concentration of MB up to $10 \mathrm{ppm}$ whereas gradual decrease was observed with increasing initial concentration. On increasing dye concentration the MB molecules begin to absorb light and so the catalyst cannot absorb sufficient light and thus the dye removal efficiency of the catalyst reduced. This also because of the adsorption of large number of $\mathrm{MB}$ molecules on the surface of $\mathrm{Zn}_{2} \mathrm{SnO}_{4} \mathrm{NC}$ at higher concentration results into the blocking of the active sits and thus reduce the degradation[28].

\subsection{2. pH study}

The $\mathrm{pH}$ of the solution is the key parameter that significantly affects surface properties of catalyst. The $\mathrm{pH}$ study on photocatalytic degradation of $\mathrm{MB}$ was evaluated in $\mathrm{pH}$ range of 3 to 11 using $10 \mathrm{ppm}$ dye solution and exposed $20 \mathrm{mg}$ of $\mathrm{Zn}_{2} \mathrm{SnO}_{4} \mathrm{NC}$ as shown in Fig. 6(C). The upshots inferred that the percentage degradation of $\mathrm{MB}$ was maximum at $\mathrm{pH} 9$ as compared to other studied $\mathrm{pH}$. MB being a cationic dye shows maximum degradation in the alkaline medium and maximum degradation is exhibited at $\mathrm{pH} 9$ and the activity decreased with further increased. The enhanced activity at $\mathrm{pH}$ is attributed to formation of hydroxyl ions that are accountable for 
the production of hydroxyl radicals. The low degradation at $\mathrm{pH} 11$ is might be due to the dissociation of $\mathrm{Zn}_{2} \mathrm{SnO}_{4} \mathrm{NC}$, thus optimum $\mathrm{pH}$ for the degradation of $\mathrm{MB}$ is 9[29].

\subsubsection{Reusability study}

The stability of the $\mathrm{Zn}_{2} \mathrm{SnO}_{4}$ NPs in term of its reusability was analyzed against the five-fold degradation of the MB. The experiment was performed by the addition of fresh MB solution by degrading the previous one under same conditions for five times. The Fig. 6(d) shows that there is a negligible reduction in the efficiency of the $\mathrm{Zn}_{2} \mathrm{SnO}_{4}$ catalystafter three cycles and decrease on the efficiency of the catalyst that is ascribed to the surface coverage of the catalyst. Overlooking to the photocatalytic efficiency, the $\mathrm{Zn}_{2} \mathrm{SnO}_{4} \mathrm{NCis}$ the most appropriate catalyst to be used for degradation of organic pollutants under simulated solar light and it can be effectively used for various stage reactions.

\section{(Position for Fig. 6)}

\subsubsection{Photocatalytic mechanism}

Photocatalysis is a kind of reaction that proceeds on the expense of energy that is equal or higher than the band gap of the catalyst. The electrons move from the valance band to the conduction band on irradiating of semiconductor with a light source. After effect equal number of holes are engendered in valence band. All types of microbial, organic, and inorganic contaminants owing to their redox potential are degrading via photo-generated holes and electrons. They react with adsorbed electron acceptors and electron donors by migrating to the surface to produce hydroxyl radicals, hydrogen peroxides, superoxide radical anions. The hydroxyl radical reacts with aqueous solution resultantly producing innocuous compounds. Under same reaction conditions, the organic pollutants are thoroughly oxidized to halide ions, $\mathrm{H}_{2} \mathrm{O}$ and $\mathrm{CO}_{2}$ on negligible production of displeasing by-products [9]. In the present study, the reaction mixture was irradiated with the simulated solar light and the electrons of both the oxides get excited to conduction and the holes are generated in the valance band. The electrons and the holes are adequately separated as the holes get assembled in the $\mathrm{VB}$ of $\mathrm{ZnO}$ while they were generated in the $\mathrm{VB}$ of $\mathrm{SnO}_{2}$ similarly, electrons get shifted to the $\mathrm{CB}$ of $\mathrm{SnO}_{2}$ from the $\mathrm{CB}$ of $\mathrm{ZnO}$. Later the ${ }^{\bullet} \mathrm{OH}$ and $\mathrm{O}_{2}{ }^{\bullet}$ are produced by the reaction of holes $\left(\mathrm{h}^{+}\right)$and electrons $\left(\mathrm{e}^{-}\right)$with the water and 
absorbed oxygen respectively. The $\mathrm{O}_{2}^{-\bullet}$ free radical serve as an additional source of producing $\bullet$ OH radicals which then lead to the degradation of the MB to non-toxic material [16].

\section{Conclusion}

The manipulation of plant materials for the fabrication of nanomaterials is the most effective, economical and nontoxic route. The investigated physicochemical properties confirm the highly crystalline nature of $\mathrm{Zn}_{2} \mathrm{SnO}_{4} \mathrm{NC}$ with band gap of $3.13 \mathrm{eV}$ was found most efficient catalyst for the photodegradation of $\mathrm{MB}$. The operational parameters like $\mathrm{pH}$, initial concentration of $\mathrm{MB}$ and catalyst dose govern the photocatalytic mineralization of MB. The photocatalytic reaction was found to follow first order kinetic and $96 \% \mathrm{MB}$ was deteriorated in 80 min with the rate of degradation $0.038 \mathrm{~min}^{-1}$ at $\mathrm{pH} 9$ and catalyst dose of $20 \mathrm{mg}$. This study reveals that the $\mathrm{Zn}_{2} \mathrm{SnO}_{4}$ $\mathrm{NC}$ is an efficient, economical and stable photocatalyst for the remediation of organic pollutants.

\section{References}

[1] A. Salama, A. Mohamed, N.M. Aboamera, T.A. Osman, A. Khattab, Photocatalytic degradation of organic dyes using composite nanofibers under UV irradiation, Applied Nanoscience (Switzerland). 8 (2018) 155-161. doi:10.1007/s13204-018-0660-9.

[2] D.N. S, Impact of Dyeing Industry Effluent on Groundwater Quality by Water Quality Index and Correlation Analysis Journal of Pollution Effects \& Control, 2 (2014) 2-5. doi:10.4172/2375-4397.1000126.

[3] P. Zhu, Z. Ren, R. Wang, M. Duan, L. Xie, J. Xu, Preparation and visible photocatalytic dye degradation of, 14 (2020) 33-42.

[4] H. Anwer, A. Mahmood, J. Lee, K. Kim, J. Park, A.C.K. Yip, Photocatalysts for degradation of dyes in industrial effluents : Opportunities and challenges, 12 (2019) 955972.

[5] T. Liu, Y. Li, Q. Du, J. Sun, Y. Jiao, G. Yang, Z. Wang, Y. Xia, W. Zhang, K. Wang, H. Zhu, D. Wu, Adsorption of methylene blue from aqueous solution by graphene, Colloids and Surfaces B: Biointerfaces. 90 (2012) 197-203. doi:10.1016/j.colsurfb.2011.10.019.

[6] Y. Li, Q. Du, T. Liu, X. Peng, J. Wang, J. Sun, Y. Wang, S. Wu, Z. Wang, Y. Xia, L. Xia, 
Comparative study of methylene blue dye adsorption onto activated carbon, graphene oxide, and carbon nanotubes, Chemical Engineering Research and Design. 91 (2013) 361368. doi:10.1016/j.cherd.2012.07.007.

[7] M. Fakhrzad, A.H. Navidpour, M. Tahari, S. Abbasi, Synthesis of Zn2SnO4 nanoparticles used for photocatalytic purposes, Materials Research Express. 6 (2019). doi:10.1088/2053-1591/ab2eb5.

[8] I. Khan, K. Saeed, I. Khan, Nanoparticles: Properties , applications and toxicities, Arabian Journal of Chemistry. 12 (2019) 908-931. doi:10.1016/j.arabjc.2017.05.011.

[9] V.C. Padmanaban, M.S. Giri Nandagopal, G. Madhangi Priyadharshini, N. Maheswari, G. Janani Sree, N. Selvaraju, Advanced approach for degradation of recalcitrant by nanophotocatalysis using nanocomposites and their future perspectives, International Journal of Environmental Science and Technology. 13 (2016) 1591-1606. doi:10.1007/s13762-016-1000-9.

[10] S. Danwittayakul, M. Jaisai, T. Koottatep, J. Dutta, Enhancement of photocatalytic degradation of methyl orange by supported zinc oxide nanorods/zinc stannate (ZnO/ZTO) on porous substrates, Industrial and Engineering Chemistry Research. 52 (2013) 1362913636. doi:10.1021/ie4019726.

[11] S. Sagadevan, J. Singh, K. Pal, Z. Zaman, Hydrothermal synthesis of zinc stannate nanoparticles spectroscopic investigation, Journal of Materials Science: Materials in Electronics. 0 (2017) 0. doi:10.1007/s10854-017-6916-4.

[12] S.S. Nalimova, A.I. Maksimov, L.B. Matyushkin, V.A. Moshnikov, Current State of Studies on Synthesis and Application of Zinc Stannate ( Review ), 45 (2019) 251-260. doi:10.1134/S1087659619040096.

[13] S. Baruah, J. Dutta, Zinc Stannate Nanostructures : Hydrothermal Synthesis Zinc stannate nanostructures : hydrothermal synthesis, (2011). doi:10.1088/1468-6996/12/1/013004.

[14] V.N. Kalpana, V.D. Rajeswari, A Review on Green Synthesis , Biomedical Applications, and Toxicity Studies of ZnO NPs, 2018 (2018). 
[15] C.M. Chetty, Antioxidant Properties of Ficus Species - A Review, 2 (2010) 2174-2182.

[16] S. Shoukat, W. Rehman, S. Haq, M. Waseem, A. Shah, Synthesis and characterization of zinc stannate nanostructures for the adsorption of chromium (VI) ions and photodegradation of rhodamine 6G, Materials Research Express. 6 (2019) 1-12. doi:10.1088/2053-1591/ab473c.

[17] M. Dehbashi, M. Aliahmad, Experimental study of structural and optical band gap of nickel doped tin oxide nanoparticles, International Journal of Physical Sciences. 7 (2012) 5415-5420. doi:10.5897/IJPS11.1606.

[18] F. Gu, S.F. Wang, C.F. Song, M.K. Lü, Y.X. Qi, G.J. Zhou, D. Xu, D.R. Yuan, Synthesis and luminescence properties of SnO2 nanoparticles, Chemical Physics Letters. 372 (2003) 451-454. doi:10.1016/S0009-2614(03)00440-8.

[19] V. Vinoth, T. Sivasankar, A.M. Asiri, J.J. Wu, K. Kaviyarasan, S. Anandan, Photocatalytic and photoelectrocatalytic performance of sonochemically synthesized Cu2O@TiO2 heterojunction nanocomposites, Ultrasonics Sonochemistry. 51 (2018) 223229. doi:10.1016/j.ultsonch.2018.10.022.

[20] B. Venugopal, B. Nandan, A. Ayyachamy, V. Balaji, S. Amirthapandian, B.K. Panigrahi, T. Paramasivam, Influence of manganese ions in the band gap of tin oxide nanoparticles: structure, microstructure and optical studies, RSC Advances. 4 (2014) 6141. doi:10.1039/c3ra46378h.

[21] B. Baruwati, D.K. Kumar, S. V. Manorama, Hydrothermal synthesis of highly crystalline $\mathrm{ZnO}$ nanoparticles: A competitive sensor for LPG and EtOH, Sensors and Actuators, B: Chemical. 119 (2006) 676-682. doi:10.1016/j.snb.2006.01.028.

[22] M. Zhang, T. An, X. Hu, C. Wang, G. Sheng, J. Fu, Preparation and photocatalytic properties of a nanometer $\mathrm{ZnO}-\mathrm{SnO} 2$ coupled oxide, Applied Catalysis A: General. 260 (2004) 215-222. doi:10.1016/j.apcata.2003.10.025.

[23] M.B. Ali, F. Barka-Bouaifel, H. Elhouichet, B. Sieber, A. Added, L. Boussekey, M. Ferid, R. Boukherroub, Hydrothermal synthesis, phase structure, optical and photocatalytic 
properties of $\mathrm{Zn} 2 \mathrm{SnO} 4$ nanoparticles, Journal of Colloid And Interface Science. 457 (2015) 360-369. doi:10.1016/j.jcis.2015.07.015.

[24] S. Haq, W. Rehman, M. Waseem, R. Javed, Mahfooz-ur-Rehman, M. Shahid, Effect of heating on the structural and optical properties of $\mathrm{TiO} 2$ nanoparticles: antibacterial activity, Applied Nanoscience. 8 (2018) 11-18. doi:10.1007/s13204-018-0647-6.

[25] A.N. Naje, A.S. Norry, A.M. Suhail, Preparation and Characterization of SnO 2 Nanoparticles, Int. J. Innov. Res. Sci. Eng. Technol. 2 (2013) 7068-7072. doi:10.1088/0957-4484/13/5/304.

[26] S. Haq, S. Shoukat, W. Rehman, M. Waseem, A. Shah, Green fabrication and physicochemical investigations of zinc-cobalt oxide nanocomposite for wastewater treatment, Journal of Molecular Liquids. $318 \quad$ (2020) 114260. doi:10.1016/j.molliq.2020.114260.

[27] M.M. Rashad, A.A. Ismail, I. Osama, I.A. Ibrahim, A.H.T. Kandil, Photocatalytic decomposition of dyes using $\mathrm{ZnO}$ doped $\mathrm{SnO}_{2}$ nanoparticles prepared by solvothermal method, Arabian Journal of Chemistry. 7 (2014) 71-77. doi:10.1016/j.arabjc.2013.08.016.

[28] S. Alkaykh, A. Mbarek, E.E. Ali-Shattle, Photocatalytic degradation of methylene blue dye in aqueous solution by $\mathrm{MnTiO}_{3}$ nanoparticles under sunlight irradiation, Heliyon. 6 (2020) e03663. doi:10.1016/j.heliyon.2020.e03663.

[29] T. Nguyen, T. Thu, N.N. Thi, V.T. Quang, K. Nguyen, Synthesis, characterisation, and effect of $\mathrm{pH}$ on degradation of dyes of copper-doped $\mathrm{TiO}_{2}$, Journal of Experimental Nanoscience. 11 (2016) 226-238. doi:10.1080/17458080.2015.1053541. 


\section{List of Figures}

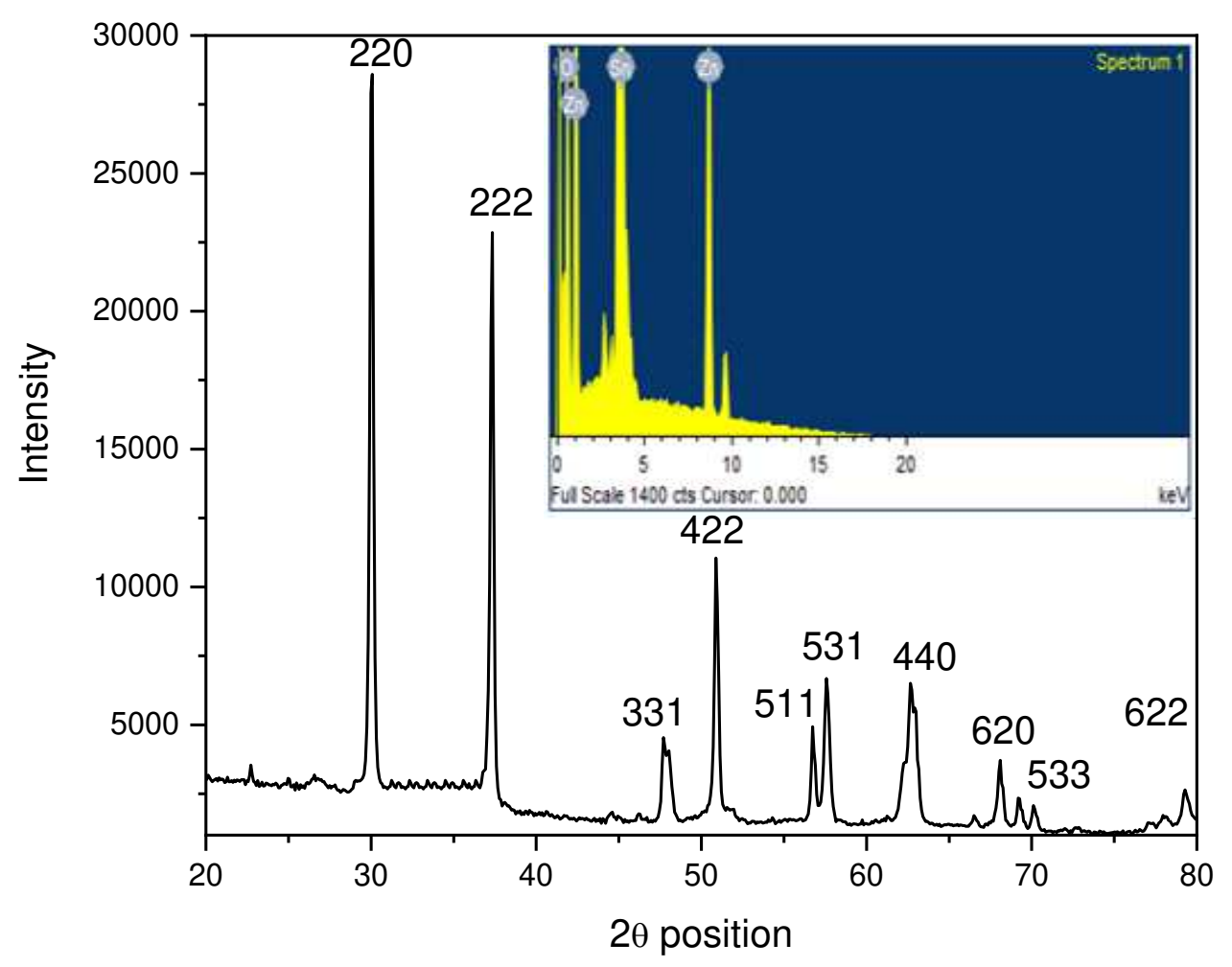

Fig. 1: XRD diffractogram (inset: $\mathrm{EDX}$ spectrum) of $\mathrm{Zn}_{2} \mathrm{SnO}_{4} \mathrm{NC}$

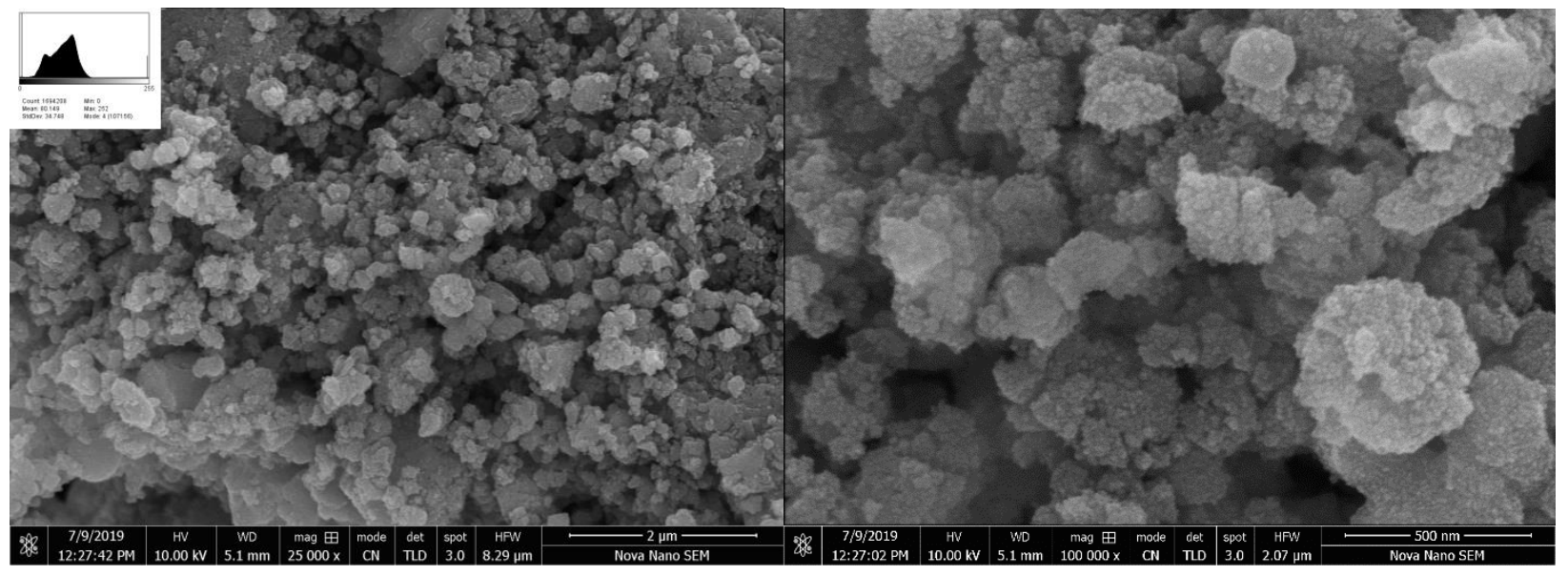

Fig. 2: Low (a) (inset: histogram) and High (b) magnification SEM micrographs of $\mathrm{Zn}_{2} \mathrm{SnO}_{4} \mathrm{NC}$ 


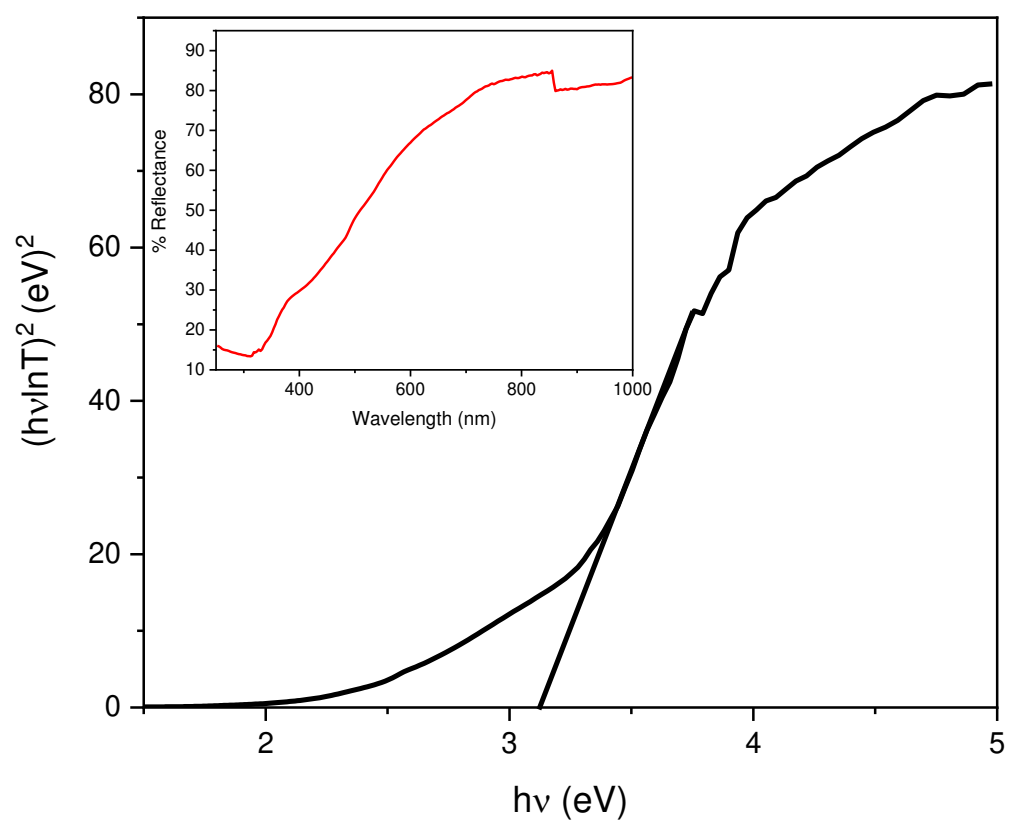

Fig. 3: Tauc's plot (inset: DRS spectrum) of $\mathrm{Zn}_{2} \mathrm{SnO}_{4} \mathrm{NC}$

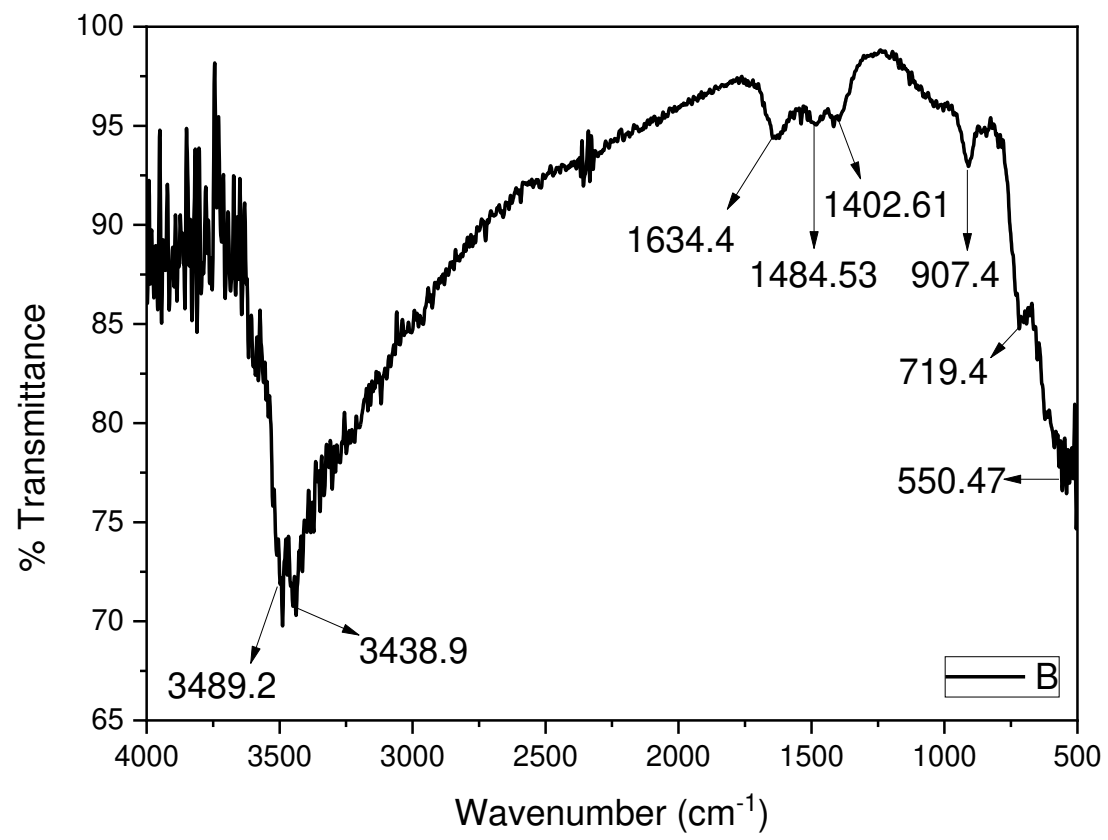

Fig. 4: FTIR spectrum of $\mathrm{Zn}_{2} \mathrm{SnO}_{4} \mathrm{NC}$ 

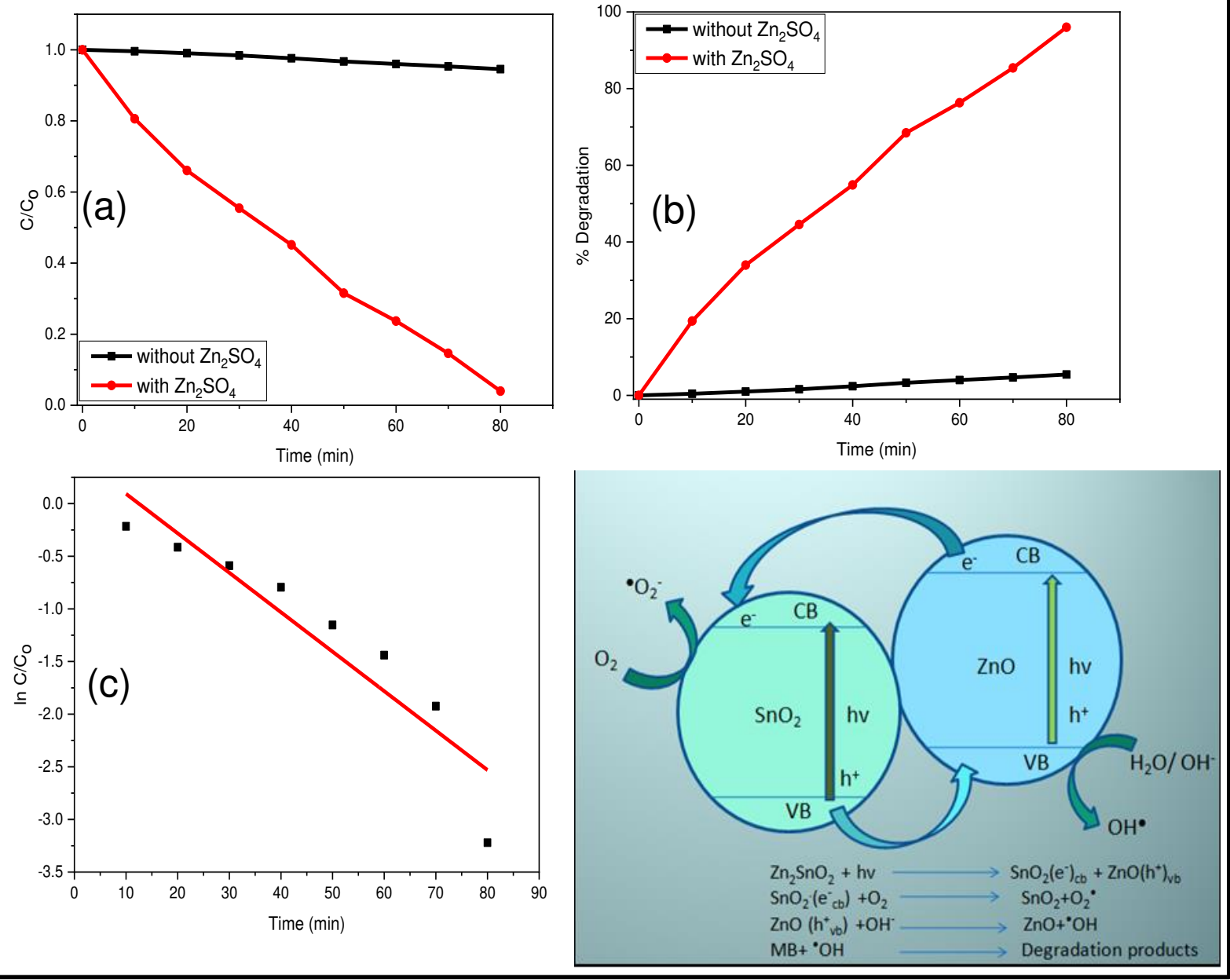

Fig. 5: Degradation profile $\left(\mathrm{C} / \mathrm{C}_{0}\right)(\mathrm{a})$, percentage degradation (b), kinetic plot (c) and schematic degradation mechanism of $\mathrm{MB}$ in the presence of $\mathrm{Zn}_{2} \mathrm{SnO}_{4} \mathrm{NC}$ 

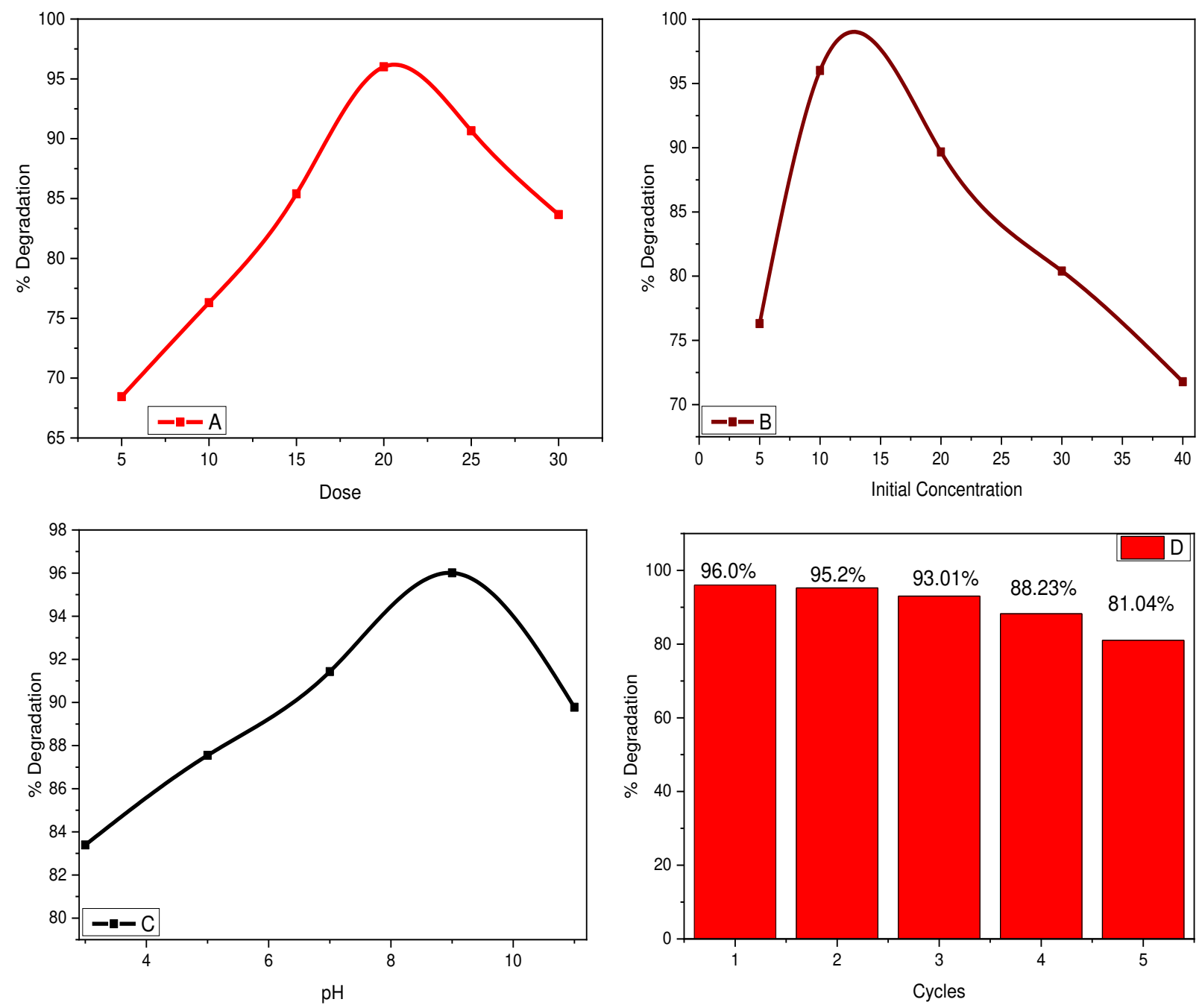

Fig. 6: percentage degradation of MB at different catalyst dose (a), initial concentration (b), $\mathrm{pH}$ (c) and cycles (d) of photocatalytic degradation. 
Figures

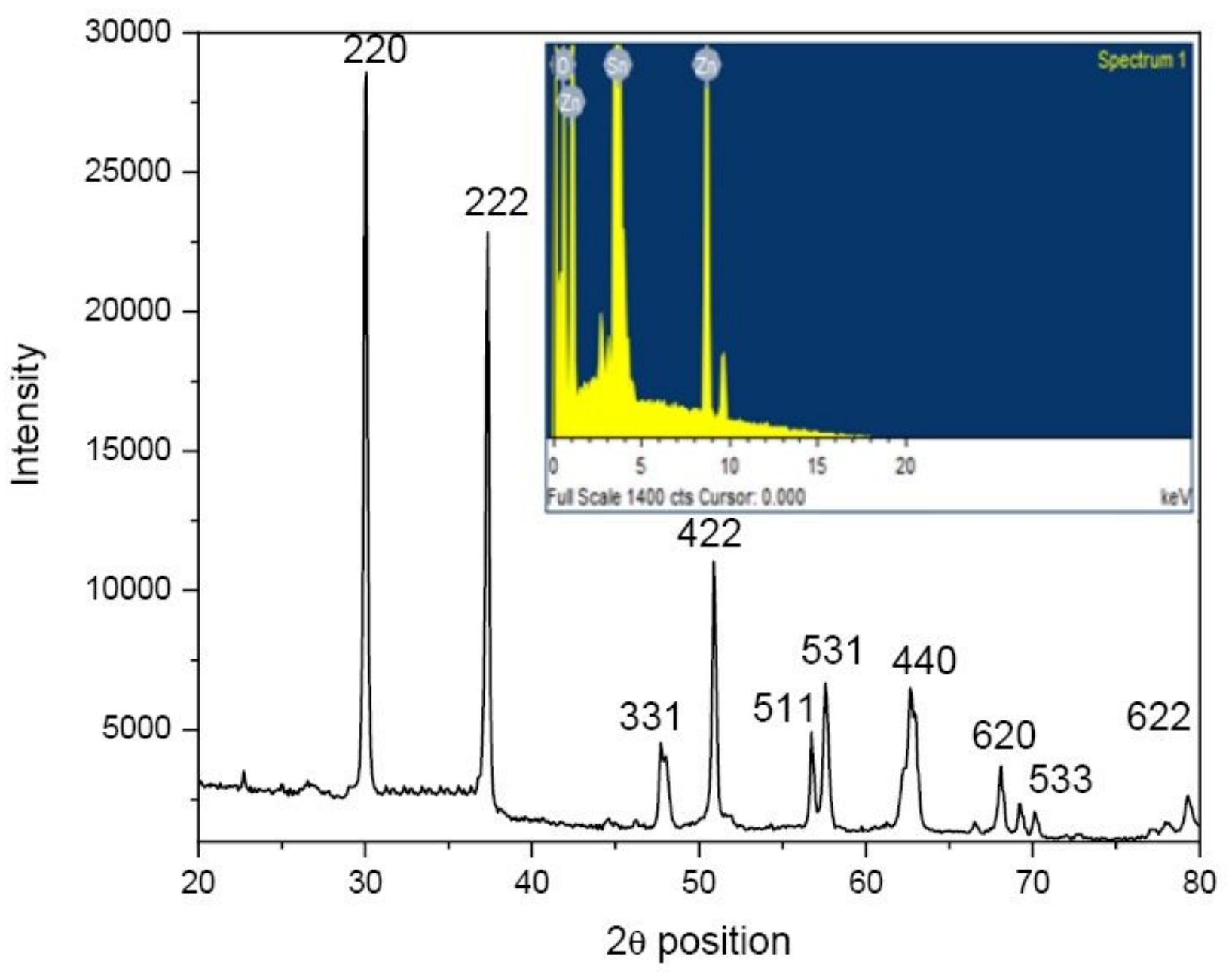

Figure 1

XRD diffractogram (inset: EDX spectrum) of Zn2SnO4 NC 


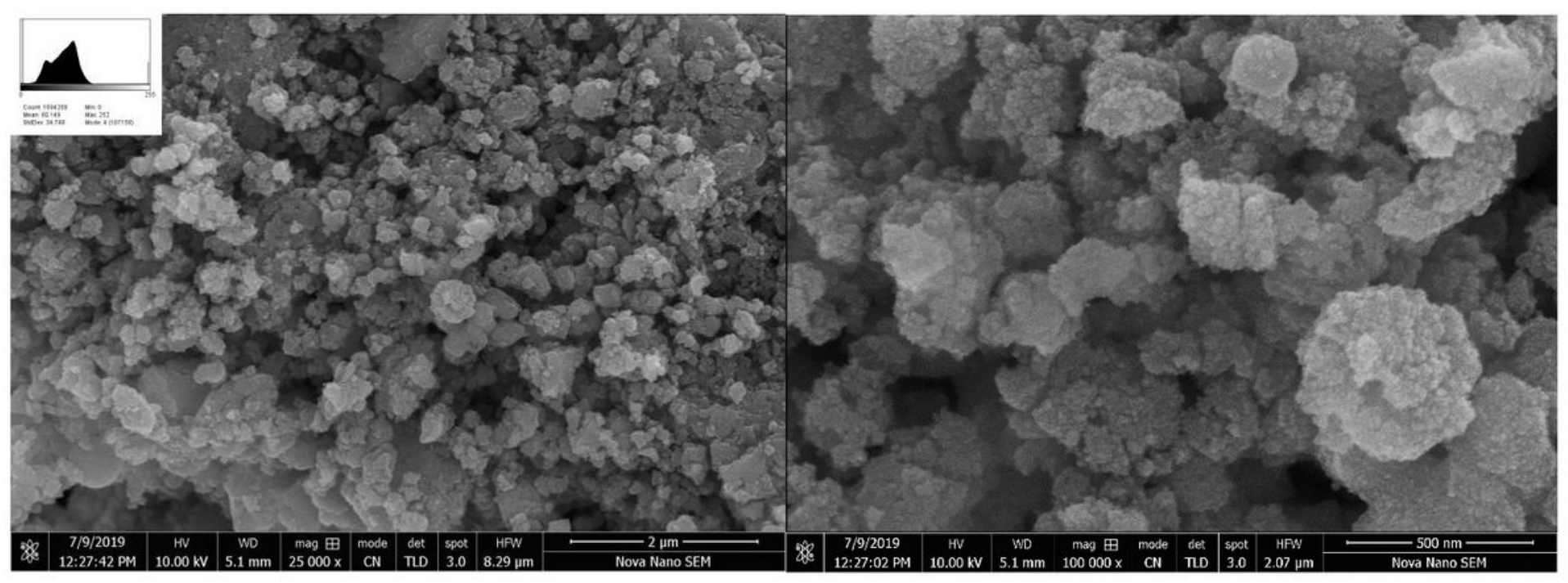

Figure 2

Low (a) (inset: histogram) and High (b) magnification SEM micrographs of Zn2SnO4 NC 


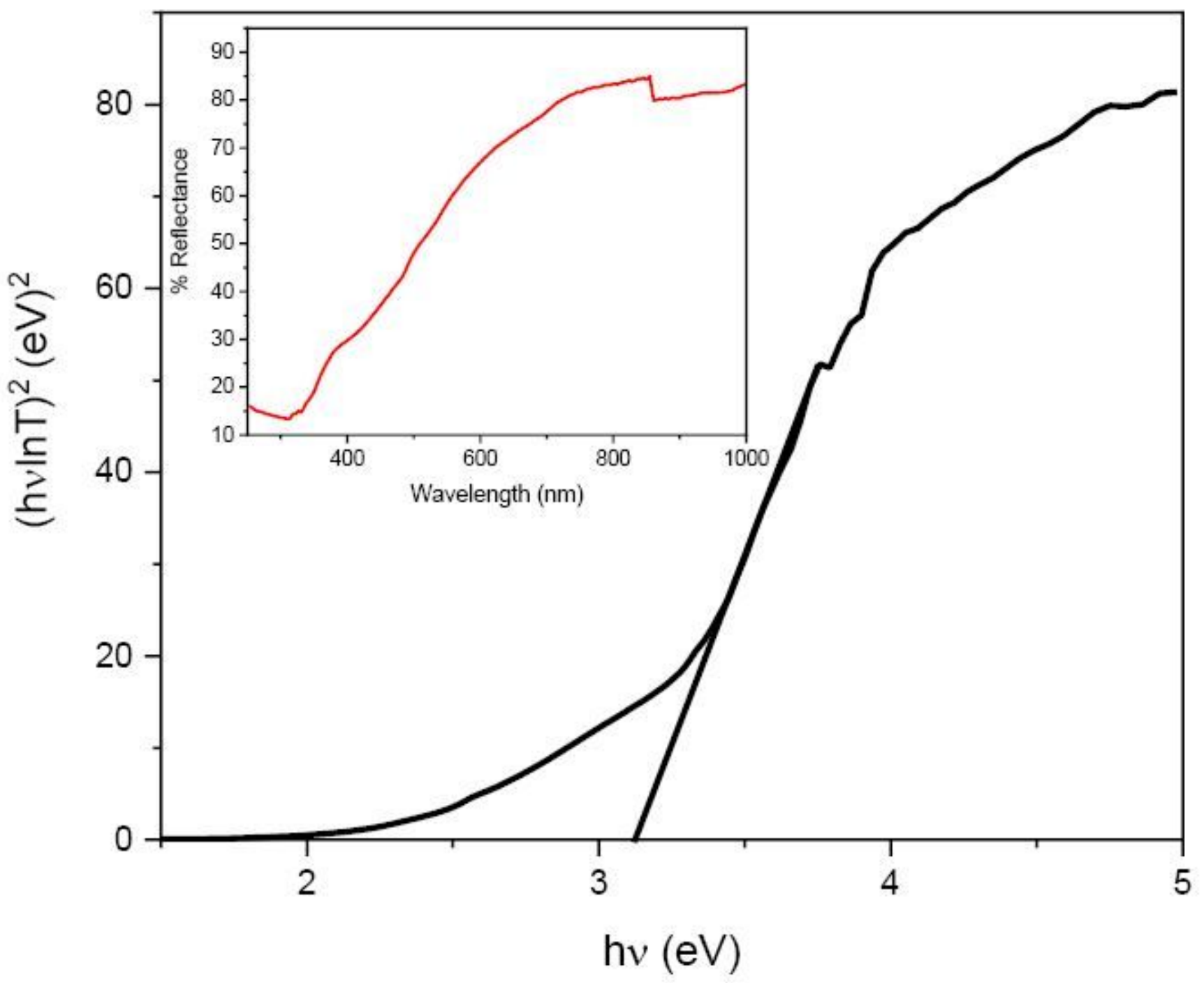

Figure 3

Tauc's plot (inset: DRS spectrum) of Zn2SnO4 NC 


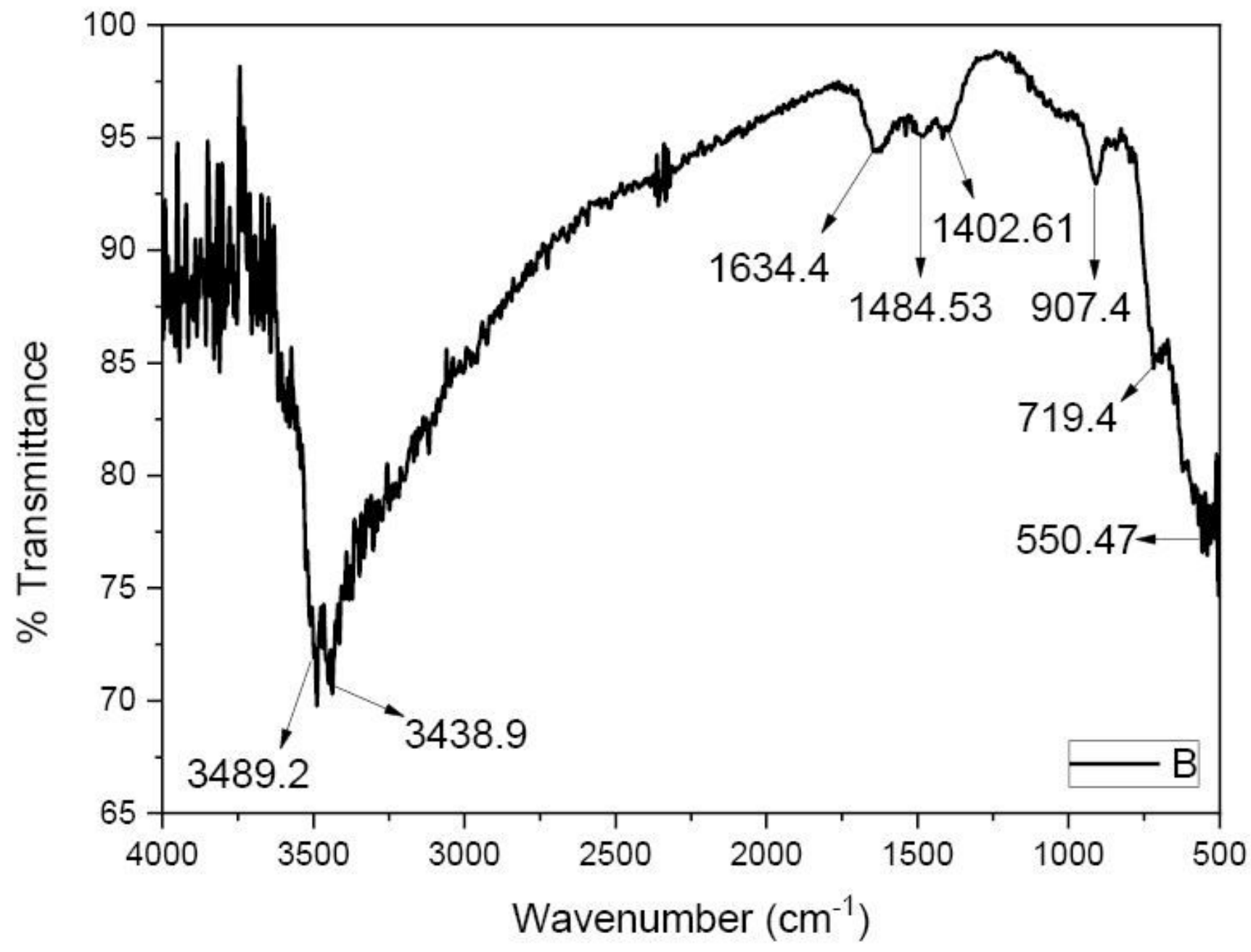

Figure 4

FTIR spectrum of Zn2SnO4 NC 

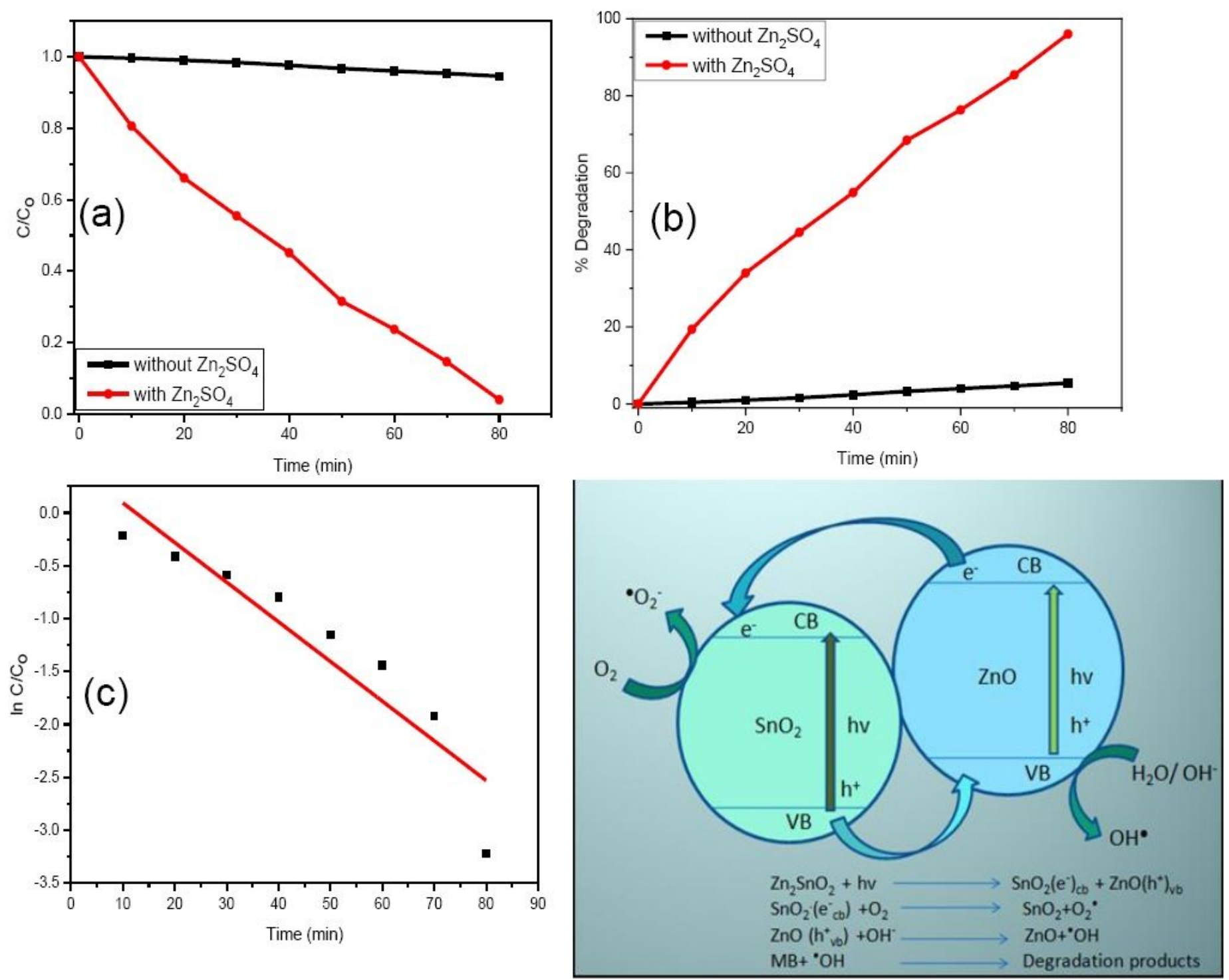

\section{Figure 5}

Degradation profile $(\mathrm{C} / \mathrm{Co})(\mathrm{a})$, percentage degradation (b), kinetic plot (c) and schematic degradation mechanism of $\mathrm{MB}$ in the presence of $\mathrm{Zn} 2 \mathrm{SnO} 4 \mathrm{NC}$ 

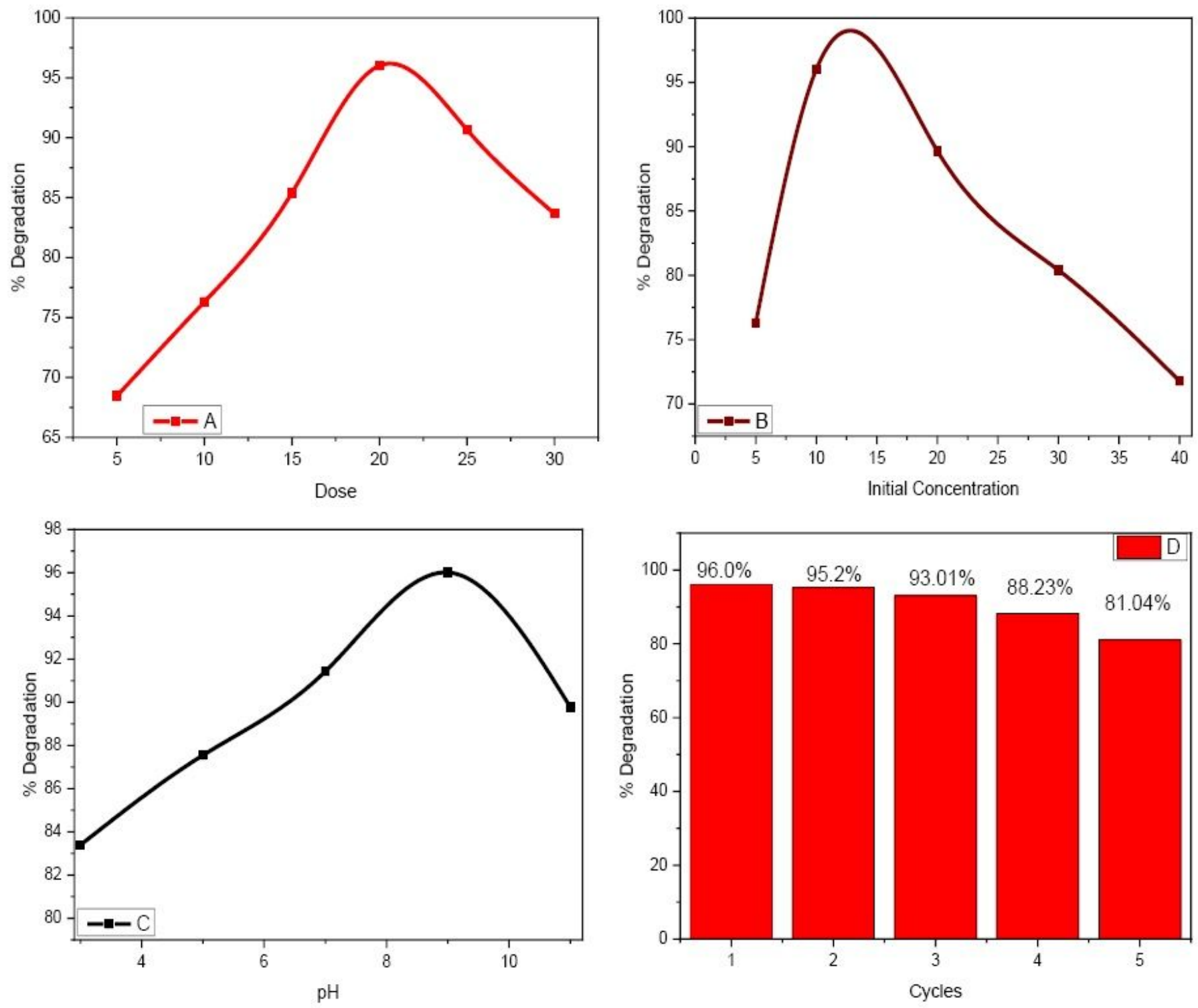

Figure 6

percentage degradation of MB at different catalyst dose (a), initial concentration (b), $\mathrm{pH}$ (c) and cycles (d) of photocatalytic degradation. 